International Journal of Management Science

and Business Administration

Volume 1, Issue 2, January 2015, Pages 71-83

\title{
Building a Framework for Market Orientation Impact on Radical and Incremental Marketing Innovation Research
}

\author{
Alshahry Abdullah, Wang Aimin \\ School of Management, Wuhan University of Technology, Wuhan, China \\ Corresponding author (e-mail):aboodi_besha@hotmail.com
}

\begin{abstract}
With the privatization of the health sector and an overall trend in health care where the servicing of the patients and illness prevention is becoming a major source of industry's revenue, marketing innovation to attract new customers is becoming increasingly relevant for organizational performance and financial results of hospitals. Consequently, offering an innovative and superior marketing mix for the customers is a necessary requirement for market competitiveness. Marketing operations and market orientation should, therefore, aim to boost the marketing innovation of hospitals. In this paper, we built a research framework to measure influence of market orientation on marketing innovation in Saudi Arabian hospitals. By determining the relationship between the market orientation factors, centralization, formalization and marketing innovation, organizations will know which aspect of market orientation to focus on. A six-step research framework has been proposed which will help to explain the impact of customer orientation, inter-functional orientation and competitor orientation on marketing innovation together with the moderating effects of centralization and formalization on those relationships. The findings of the future study may suggest an important role of market orientation for an effective innovation generation and business performance of hospitals in Saudi Arabia.
\end{abstract}

Key words: Research framework, Market orientation impact, Marketing innovation, Centralization, Formalization

\section{Introduction}

In the last decades, we have seen an evolution of the service sector's role in the economy, its relevance in increasing innovation, competitiveness, employment and economic growth (Hauknes, 1998; de Jong, Bruins, Dolfsma and Meijaard, 2003; Howells and Tether, 2004; Tether, 2005). From the growing importance of this sector, it becomes important to analyze the determinant factors of innovative capability of service firms in particular. The importance of the innovation process in services is widely recognized, 
both theoretically and empirically, but the heterogeneity of the service sector and the lack of an innovation typology that allows integration of that diversity make theoretical teaching and empirical analyses difficult. The literature demonstrates a growing interest in the study of innovation in services. The service sector covers a wide range of different activities with greatly differentiating characteristics (Hauknes, 1998; Drejer, 2004).

In addition to innovations in products and production processes, in a market economy, there are also innovations in the marketing of products. The development of new marketing tools and methods plays an important role in the evolution of industries. In recent years, for instance, new ways of gathering consumer information through innovative marketing programs and technologies have enabled firms to reach consumers more effectively and to use new trading formats and techniques. However, despite its obvious importance, unlike product or process innovation, marketing innovation has received little attention in the economics literature. The purpose of this paper is to make a contribution to the economic analysis of marketing innovation by establishing a research framework that will enable explanation of the variables that influence marketing innovation.

Research in the context of health sector, which is usually publicly financed, is scarce, especially in the context of Arabic countries and Saudi Arabia. Therefore, our study has both descriptive and explorative value. Our research has mainly addresses the link between market orientation variables, market and incremental innovation, how the aforementioned orientation processes affect the innovation process itself. Also, another objective of the study is to determine the current state of marketing innovation in the Saudi Arabian hospitals. The main research questions included are: which type of market orientation causes radical innovation and incremental innovation, what is the moderating influence of formalization and centralization of processes on a relationship between marketing orientation and innovation, what is the current level of incremental and radical marketing innovation of Saudi Arabia hospitals, if existent, what are the main reasons of insufficient marketing innovation in Saudi Arabia hospitals and how does the current condition of the health sector, i.e., Saudi Arabian hospitals correlate to the marketing innovation process. Our aim is to explore how different variables that are consumer and competitor orientation, interfunctional coordination, centralization and formalization affect radical and incremental innovation, the factors which influence such process and the strength of the connection of these variables in the context of hospital sector in Saudi Arabia.

\section{Market orientation - marketing innovation research model construction}

\subsection{Marketing orientation theory}

The theoretical foundation of the research is based on the market orientation and marketing innovation theories and complemented with centralization and formalization variables. Narver and Slater, as well as Kohli and Jaworski, explained the concept of market orientation as a certain behavior. According to Slater and Narver "because a market orientation essentially involves doing something new or different in response to market conditions, it may be viewed as a form of innovative behavior". The accessible 
empirical investigations of the association between market orientation and company performance tend to draw general conclusions about this association as no effort has been made to examine the nature and the importance of this association in specific market environments (e.g., industrial markets vs. consumer markets). Market orientation is an important element of the organizational structure. Kohli and Jaworski (1990) define market orientation as "the organization-wide generation of market intelligence, dissemination of its intelligence across departments, and organization-wide responsiveness to it."

A market-oriented organization is considered to be an "open system". This means that a market-oriented organization emphasizes interaction with the environment as essential for its functioning (Scott, 1992). This differs with an organization that is oriented to internally driven optimization and, thus, seeks to defend itself against the environment. Market orientation, more specifically, involves generation and dissemination of market intelligence that is composed of information about the external environment confronting an organization, sharing of this information among all functions in an organization and rapid managerial action in response to this information. An organization that is market oriented also possesses a strong long-term orientation to ensure that preferences of current and potential customers are identified, as also the ability of current and potential competitors to satisfy these preferences. Finally, a marketoriented organization exhibits a determined orientation toward profitability to ensure that the resources necessary to support the information collection, dissemination, and organizational response activities are available (Kohli \& Jaworski, 1990; Narver \& Slater, 1990). In our research we have followed the three dimensions of market orientation favored by Narver and Slater to build the research model. A market oriented hospital is expected to use its market information to achieve operation efficiency because it is likely that such a firm understands that value can be created for buyers not only by additional benefits but also by reducing their acquisition and use costs (Narver and Slater 1990). Additionally, a market oriented company puts the customer at the "heart" of the business ( Kohli \& Jaworski, 1990; Narver \& Slater, 1990); all activities in the organization are based around the customer.

\subsection{Innovation theory}

Innovation is generally quite important for business performance, both radical and incremental. Radical innovation provides something new to the world that we live in. This type of innovation is sometimes referred as breakthroughs, discontinuous or disruptive innovation (Jerry, Mahajan 1997) Due to a high level of uncertainties, radical innovation cannot be described by orderly process. "Even though the radical innovation life cycle includes many of the same sets of activities and decision points, the reality of managing the process is strikingly different for radical versus incremental innovation." (Utterback 1994).

Incremental innovation implies a series of small improvements to an existing product or product line. Incremental innovation is regularly used within the high technology business by companies that need to continue to improve their products to include new features increasingly desired by consumers. (Leonard 1992). Sometimes it is referred as sustaining innovation and it uses existing forms or technologies as a starting point.

On one hand, incremental innovation exploits existing technology, low uncertainty, focuses on cost or feature improvements in existing products or services, processes, marketing or business model, improves competitiveness within current markets or industries while on the other hand radical innovation explores 
new technology, high uncertainty, focuses on processes, products or services with unprecedented performance features, creates a dramatic change that transforms existing markets or industries, or creates new ones. Therefore, in the planned study we investigated both types of innovation as they are relevant for organizational performance.

\section{A six-step framework for conducting market orientation - marketing innovation research}

The six-step framework for conducting the research in order to answer research questions consists of conducting a literature review, determining the model, explaining the survey design, describing the procedure used in designing the instrument, collecting the data, providing an explanation of the statistical procedures will be used to analyze the data and explaining findings and implications.

The six-step framework of this study of market orientation effects in the Saudi Arabian hospital sector comprises different methods, procedures and strategies trying to explain relationships between variables of our model. First of all, described the area of the research is to try to create an understanding of the area. This is the basis for descriptive research (Yin, 2003; Polit D. et al. 2004). The explanatory part of our study targets at testing and proving the constructed hypothesis by measuring the relationship between variables of our research model, answering the question why, building and elaborating on different theories, trying to identify why a certain phenomenon occurs. Our approach consisted of conducting a thorough literature review, research and analysis of the subject by setting the objectives and presenting the research question and further completing them using a measurement tool through which a statistical analysis would be conducted, and finally presenting the various relationships in the presented research model. Using the proposed model the objective is to answer all the research questions, taking into account and identifying all the potential literature gaps and filling them with a specifically constructed model. All the steps of the framework are explained further.

\subsection{Step 1 and 2 - Literature review and model construction}

The foregoing analysis of the literature will examine value of market orientation variables and their connection with radical and incremental innovation and the relationship and tested a moderating effect of formalization and centralization on the relationship between market orientation variables and innovation variables with the processes of centralization and formalization, i.e., to try and establish the connection on how activities of an organization, particularly those regarding planning and decision-making, become concentrated within a particular group or keeping all of the important decision-making powers within head office or the center of the organization and depending on how work roles are structured within an organization. We utilized already defined theories in order to construct the research model. Based on prior literature review and analysis, the hypothesized model elaborates the relationship between customer orientation, competitor orientation and inter-functional coordination on radical incremental innovation through the centralization and formalization process. There is a growing interest in the concept of market orientation, as empirical evidence shows that firms with a higher market orientation obtain better market performance, thus optimizing their economic and commercial results. When a company tries to expand 
and deepen current customer relationships and the orientation that specific firm has to take when developing new customer relationships, has the potential to significantly impact overall firm performance (Kumar et al. 2006; Morgan and Hunt 1994; Palmatier et al. 2006). During a long period of time market orientation has become more and more important for the performance of firms. Market orientation has mainly been characterized to be focused on three main components: customer orientation, competitor orientation and inter-functional coordination. However a strong market orientation may not necessarily constitute a dominant market position for the firm although market orientation is defined as a business culture or behavior that leads to business success. Its influence on product innovation can result to be one way to enhance business performance. Company-wise, market orientation contributes to an improved understanding of the marketing.

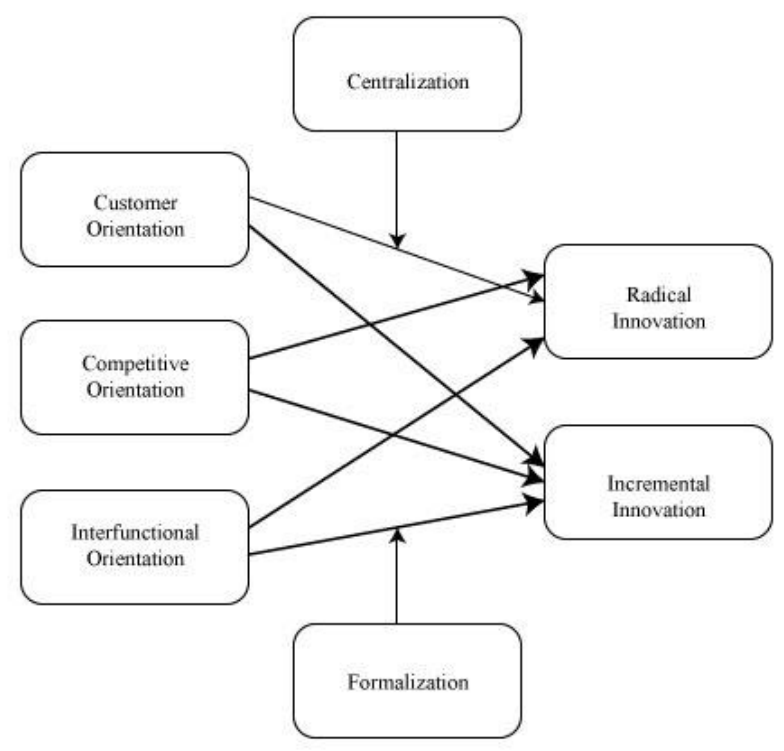

Figure 2-1 Market orientation - marketing innovation research model

H1. Customer orientation has a negative impact on radical innovation

H2. Customer orientation has a positive impact on incremental innovation

H3. Competitor orientation has a positive impact on radical innovation

H4. Competitor orientation has a positive impact on incremental innovation

H5. Inter-functional coordination has no significant impact on incremental innovation

H6. Inter-functional orientation has a positive impact radical innovation

H7. There is a negative moderating effect of centralization on the market orientation and marketing innovation relationship

H8. There is a negative moderating effect of formalization on the market orientation and marketing innovation relationship 
The refinement of the model will be performed based on the findings from the qualitative analysis. The chosen predictors are operationalized according to the existing studies with the existing scales as explained in the next section.

\subsection{Step 3-Development of the measurement instrument}

Through examining vast literature in the context of market orientation and innovation a number of empirical studies are identified. In this study, a series of indicators are used for each target construct. The measures of these constructs will be developed in several stages. First, based on the defined constructs, preliminary measures are adopted from the existing literature. The users Saudi Arabian hospitals have been selected as the data sources. As we choose to conduct a quantitative study we aimed to measure the constructs with the Likert scale. Therefore, all the scales are adopted from previous studies. Only the items and scales which proved to be valid and reliable are adopted. Some changes to the original scales are however made to suit the context of our study. The items are measured with a 7 point Likert scale, in order for the data to be normalized, with the anchors being 1 = strongly disagree, 2 = somewhat disagree, 3 = disagree, $4=$ neutral, $5=$ somewhat agree, $6=$ agree, $7=$ strongly agree. The items measured included customer and competitor orientation, formalization, centralization, inter-functional coordination, radical innovation and incremental innovation.

Some research variables are measured by multi-items, which are needed for reliability tests. The Cronbach's alpha values are applied in order to demonstrate the satisfactory level of reliability of the research variables. The data will be collected in a way that primary and secondary data will be collected, namely primary data refers to the data researcher collected by himself. The data will be collected from various sources. The sample of the research included mangers and staff who are greatly aware of the concepts of included customer and competitor orientation, formalization, centralization, inter-functional coordination, radical innovation and incremental innovation.

\subsubsection{Centralization}

Centralization of decision making will be measured by a scale that was adopted from prior studies. They developed the scale by combining two scales developed by Hage and Aiken in 1967 and used subconstruct of hierarchy of authority scale and Dewar in 1980. Some changes in the vocabulary were made in order to fit the context of our research. The scale adopted exhibited sufficient reliability (Cronbach's Alpha $=\alpha=71$ ). Centralization of decision making indicates the extent to which decision making is concentrated in an organization (Aiken and Hage 1968). This reflects the extent an employee has to follow the guidelines set by the supervisor and the control which supervisor exerts over employees' decision making. It is measured by a 5 item scale. 


\subsubsection{Formalization}

The formalization process will be measured by a scale that was developed based on the study previously done by Desphande and Zaltman. Some changes in the vocabulary are performed in order to fit the context of our research. The scale adopted showed sufficient reliability. Formalization indicates the degree to which rules define roles. authority relations, communications, norms and sanctions, and procedures, and also defines the rules and procedures which occupy a central place inside of and organizational unit (Hall, Haas, and Johnson 1967). It is measured by a 5 item scale.

\subsubsection{Customer orientation}

Customer orientation was measured by a scale adopted from Narver and Slater (1990). The scale was developed based on their definition of the whole marketing orientation process, which they consider to be an organizational culture and as the implementation of the marketing concept. There have been several changes in the vocabulary in order for it to correspond to the context of our study. The scale that will be shown demonstrated adequate reliability (Cronbach's Alpha $=(\alpha=.83)$. Customer orientation refers to a group of actions taken by a business to support its sales and service staff in considering client needs and satisfaction their major priorities. According to Kohli and Jaworski (1990), business strategies that tend to reflect a customer orientation might include: developing a quality product appreciate by consumers; responding promptly and respectfully to consumer complaints and queries; and dealing sensitively with community issues.

\subsubsection{Competitor orientation}

Competitor orientation was measured by a scale combined of two scales developed by Narver and Slater (1990) and by (Despande 1998). There will be some modification of vocabulary in order to better adapt the context of our research. The scale adopted showed sufficient reliability (Cronbach's Alpha $=\alpha=.64)$ ). Competitor orientation is where the firm directs its resources to gathering information about competitor behavior and activities. The firm's strategies would then be utilized based on the information gathered through any of these orientations. Their results are measured by a 5 item scale.

\subsubsection{Inter-functional coordination}

Inter-functional coordination was measured by a scale adopted Narver and Slater (1990). There will be some modification of the vocabulary in order to better suit the context of our study. The scale adopted demonstrated sufficient reliability (Cronbach's Alpha $=\alpha=.80$ ). Inter-functional coordination is connected with market orientation and is one of necessary principle of market orientation. It is not 
possible to use market orientation without inter-functional coordination and the very concept of market orientation is based on marketing conception.

\subsubsection{Radical innovation}

Radical innovation will be measured by a scale adopted from Dewar (2006). The scale will be a combination of scales adapted from Avlonitis et al., 2001). There was some modification of the vocabulary in order to better suit the context of our research. The scale that was adopted showed sufficient reliability (Chronbach's Alpha $=\alpha=84)$ ). Radical innovation, concerned with exploration of new technology, is fundamentally different from incremental innovation that is concerned with exploitation of existing technology. According to Dewar "Radical innovation is a product, process, or service with either unprecedented performance features or familiar features that offer potential for significant improvements in performance and cost." 1 It creates such a dramatic change in processes, products, or services that they transform existing markets or industries, or create new ones.

\subsubsection{Incremental innovation}

Incremental innovation will be measured by a scale adopted from Dewar (2006) originating from Avlonitis et al., 2001). Some changes were made in the vocabulary to better suit the context of our study. The scale that was adopted showed sufficient reliability (Chronbach's Alpha $\alpha=89$ ). The process of incremental innovation consists of a series of small improvements to an existing product or product line that usually helps maintain or improve its competitive position over time. According to Kohli and Jaworski, Incremental innovation is regularly used within the high technology business by companies that need to continue to improve their products to include new features increasingly desired by consumers.

\subsection{Step 4 - Survey Setup and Data Collection}

\subsubsection{Research Setting and Sample}

The sample includes members of the Saudi Arabian Armed Forces Hospital and other Saudi Arabian hospital in the country. The principal institution targeted will be the Armed Forces Hospital, Southern Region (AFHSR). We chose the aforementioned hospital because it is considered one of the most advanced centers in the Middle East. The respondents are key hospital managers and managerial staff from a variety of hospital departments as they are deemed to be most familiar with the factors influencing market innovation. Clearly, the groups targeted primarily concern represent the direct players in the marketing process, though the end-users can be either the hospital's staff or the patients themselves. Therefore, the stress and emphasis will be put on different staff of the hospital, meaning the managers, support, administrative and technical staff. Second sampling will be concerned with the doctors and other staff members. In our study our survey method consisted of examining a sample of key hospital managers and managerial staff from a variety of hospital departments including General Medicine, dermatology, Hematology, Neurology, General Surgery, Pediatrics, Orthopedics, Neurosurgery, Ophthalmology, 


\section{Cardiology, Oncology, Nephrology, Plastic Surgery, ENT, Urology and Oral Surgery.}

Data collection studies can be framed in both qualitative and quantitative research (Kumar Ranjit, 2010). They can be also done through the use of questionnaires (Kaynak \& Kara 2002). In this research, both primary and secondary data play a crucial role in providing answers to the research-based problem. The analysis in this study will be conducted and completed through the computation of the data in SPSS. In a way, the primary data ensure the quality in terms of validity and reliability of the research while secondary data give a thorough understanding of the concepts and models utilized to give credit to the topic. To conduct the survey concerning the market orientation variables and how they have an impact and influence marketing innovation, a questionnaire instrument will be developed and distributed online in order to collect all the necessary information for answering the given research questions.

Every variable in the marketing orientation process will be measured with an already existing multi-item scale that are adopted from different sources and adapted to fit the context of our study. This questionnaire is composed of various statements and questions, which required the Likert scale, a scale commonly involved in research that employs questionnaires, which gave all the necessary answers. All the various factors which could influence these relationships between marketing orientation variables and the innovation process itself are taken into consideration. This questionnaire will be developed and administered in English and Arabic, in case that the respondents of the questionnaire does not acquired a high enough proficiency level in English.

The questionnaire respondents within the hospitals have been selected based on their deep knowledge of the hospitals' overall marketing culture and practices. At the same time, they had to be senior enough to provide information on the Hospital. Consequently, the marketing manager and staff proved to be the appropriate individuals to contact. In order to improve the quality and clarity of the questionnaire, to make it easier to understand, suggestions and feedbacks have been solicited. After the solicitation and consultation, some of the questions will be improved and refined based on the feedback of the experts. After the comments of the experts are taken into consideration and minor modifications are performed, the final version of the questionnaire will be distributed to the participants of the study. The questionnaire will both be sent to managers of hospitals and hospital staff in general, in order to avoid the threat of common method bias. One part of the questionnaire required the respondents to give their demographic information, age, gender, occupation, career and their level of educations.

\subsection{Step 5 - Data analysis}

Next the patterns of results will be presented and analyzed for their relevance to the research issues or propositions and hypotheses. After the data has been collected and imported into Survey Monkey, an online survey platform, limited and well-reduces the problem errors which could have occurred during the data entry process. The analysis will be conducted with the latest version of SPSS statistical package. This package is widely used program for statistical analysis in social science. It is also used by market researchers, health researchers, survey companies, government, education researchers, marketing organizations, data miners, and others. (Lincoln and Guba, 1986). The research data will be screened prior to analysis. The analysis process will be conducted in three main parts. First, the normality of data has 
been assessed in order to be able to continue with further analysis. Normality assessment will then be followed by the measurement tool evaluation. The process encompassed checking for validity and reliability of the questionnaire. Finally, the structural model analysis will be performed in order to determine the predictive value of our model and the hypothesis are discussed. Analysis will be performed for only complete responses and all missing values if any are eliminated.

\subsection{Step 6 - Findings and implications}

Given the fact that different companies are characterized by different levels of marketing orientation adoption, they should be classified depending on the degree to which they have developed a marketing orientation. In the case of our research, we are trying to examine the marketing orientation variables in the case of hospital sector in Saudi Arabia. Therefore we will find out the level of market orientation, marketing innovation, centralization and formalization in different hospitals. The purpose of this study is also to identify and evaluate the current state of innovation and which processes (centralization, formalization) and what type of orientation is most conducive to marketing innovation. We will expand our understanding of the different factors which influence these processes. This study will give the answer which type of orientation our sample of hospitals in Saudi Arabia in particular should take. The outcome of this study will deepen a further understanding on the correlation and the understanding of the relationship between market orientation variables and radical and incremental innovation processes. Consequently, our findings gave us an idea on which dimensions of market orientation have a significant impact on the aspects of marketing innovation.

\section{Conclusion}

In our study we proposed a market orientation - marketing innovation research model that is aimed to answer questions on which factors are most conducive to marketing innovation in the hospital sector in Saudi Arabia. The exact steps of the research process are explained in detail thus providing a framework for the future research in this domain. Consequently, we contributed to the existing research process, market orientation, and innovation literature. In the planned study all of the steps are executed as planned yielding relevant results and findings.

\section{References}

- Abernathy, W. J., \& Utterback, J. M. (1978). Patterns of industrial innovation. Journal Title: Technology review. Ariel, 64, 254-228. Utterback, J. M. (1996). Mastering the dynamics of innovation. Harvard Business Press

- Al-Otaibi, M. B., \& Al-Zahrani, D. (2005). Evaluating e-business adoption: Opportunities and threats.

- Amara, N., \& Landry, R. (2005). Sources of information as determinants of novelty of innovation in manufacturing firms: evidence from the 1999 statistics Canada innovation survey. Technovation, 25(3), 245-259.

- Atuahene-Gima, K. (1996). Market orientation and innovation. Journal of Business Research, 35(2), 
93-103.

- Barge-Gil, A., Jesus Nieto, M., \& Santamaría, L. (2011). Hidden innovators: The role of non-R\&D activities. Technology analysis \& Strategic management, 23(4), 415-432.

- Burns, T. E., \& Stalker, G. M. (1961). The management of innovation. University of Illinois at Urbana-Champaign's Academy for Entrepreneurial Leadership Historical Research Reference in Entrepreneurship.

- Carmona-Lavado, A., Cuevas-Rodríguez, G., \& Cabello-Medina, C. (2010). Social and organizational capital: Building the context for innovation. Industrial Marketing Management, 39(4), 681-690.

- Chang, H. F. (1995). Patent scope, antitrust policy, and cumulative innovation. The RAND Journal of Economics, 34-57.

- Chang, Y. C. (2003). Benefits of co-operation on innovative performance: evidence from integrated circuits and biotechnology firms in the UK and Taiwan. R\&D Management, 33(4), 425437.

- Chang, Y. C., \& Chen, M. H. (2004). Comparing approaches to systems of innovation: the knowledge perspective. Technology in Society, 26(1), 17-37.

- Chang, S. J., Chung, C. N., \& Mahmood, I. P. (2006). When and how does business group affiliation promote firm innovation? A tale of two emerging economies. Organization Science, 17(5), 637656.

- Christensen, C. M., Horn, M. B., \& Johnson, C. W. (2008). Disrupting class: How disruptive innovation will change the way the world learns (Vol. 98). New York: McGraw-Hill.

- Christensen, C. M., Bohmer, R., \& Kenagy, J. (2000). Will disruptive innovations cure health care?. Harvard business review, 78(5), 102-112.

- Coenen, L., \& Díaz López, F. J. (2010). Comparing systems approaches to innovation and technological change for sustainable and competitive economies: an explorative study into conceptual commonalities, differences and complementarities. Journal of Cleaner Production, 18(12), 1149-1160.

- Cuervo-Cazurra, A., \& Genc, M. (2008). Transforming disadvantages into advantages: developingcountry MNEs in the least developed countries. journal of international Business Studies, 39(6), 957-979.

- Diaz-Balteiro, L., Casimiro Herruzo, A., Martinez, M., \& Gonzalez-Pachon, J. (2006). An analysis of productive efficiency and innovation activity using DEA: An application to Spain's wood-based industry. Forest Policy and Economics, 8(7), 762-773.

- Drucker, P. F., \& Drucker, P. F. (2007). Innovation and entrepreneurship: Practice and principles. Routledge.

- Drucker, P. F. (1988). The coming of the new organization.

- Drucker, P. F. (1964). Managing for results: economic tasks and risk-taking decisions. Routledge.

- Drucker, P. (2013). People and performance. Routledge.

- Drucker, H., Wu, S., \& Vapnik, V. N. (1999). Support vector machines for spam categorization. Neural Networks, IEEE Transactions on, 10(5), 1048-1054.

- Fukuyama, F. (2001). Social capital, civil society and development. Third world quarterly, 22(1), 720.

- Gallagher, S., \& Park, S. H. (2002). Innovation and competition in standard based industries: a historical analysis of the US home video game market. Engineering Management, IEEE 
Transactions on, 49(1), 67-82.

- Gallagher, K. S., Holdren, J. P., \& Sagar, A. D. (2006). Energy-technology innovation. Annu. Rev. Environ. Resour., 31, 193-237.

- Hitt, M. A., Hoskisson, R. E., \& Ireland, R. D. (1994). A mid-range theory of the interactive effects of international and product diversification on innovation and performance. Journal of management, 20(2), 297-326.

- Hooley, G. J., Lynch, J. E., \& Shepherd, J. (1990). The marketing concept:putting the theory into practice. European Journal of Marketing, 24(9), 7-24.

- Hooley, G., Cox, T., Fahy, J., Shipley, D., Beracs, J., Fonfara, K., \& Snoj, B.(2000). Market Orientation in the Transition Economies of Central Europe:: Tests of the Narver and Slater Market Orientation Scales. Journal of Business Research, 50(3), 273-285.

- Hunt, S. D., \& Morgan, R. M. (1996). The resource-advantage theory of competition: dynamics, path dependencies, and evolutionary dimensions. The Journal of marketing, 107-114.

- Jeffrey Thieme, R., Michael Song, X., \& Shin, G. C. (2003). Project management characteristics and new product survival. Journal of Product Innovation Management, 20(2), 104-119.

- Kumar, S., \& Phrommathed, P. (2005). Research methodology (pp. 43-50). Springer US.

- Landry, R., Amara, N., \& Lamari, M. (2002). Does social capital determine innovation? To what extent?. Technological forecasting and social change, 69(7), 681-701.

- Llas, M., Gleiser, P. M., López, J. M., \& Díaz-Guilera, A. (2003). Nonequilibrium phase transition in a model for the propagation of innovations among economic agents. Physical Review E, 68(6), 066101.

- $\quad$ Lipsett, M. S., Holbrook, J. A., Lipsey, R. G., \& de Wit, R. W. (1995). R\&D and innovation at the firm level: improving the S\&T policy information base. Research Evaluation, 5(2), 123-129.

- Nieto, M. J., \& Santamaría, L. (2007). The importance of diverse collaborative networks for the novelty of product innovation. Technovation, 27(6), 367-377.

- Nieto, M. J., \& Santamaría, L. (2010). Technological Collaboration: Bridging the Innovation Gap between Small and Large Firms*. Journal of Small Business Management, 48(1), 44-69.

- Nieto, M. J., \& Santamaría, L. (2007). The importance of diverse collaborative networks for the novelty of product innovation. Technovation, 27(6), 367-377.

- Nieto, M. J., \& Rodríguez, A. (2011). Offshoring of R\&D: Looking abroad to improve innovation performance. Journal of International Business Studies, 42(3), 345-361.

- Nieto, M. J., \& Santamaría, L. (2005). Novelty of product innovation: the role of different networks.

- Parasuraman, A., Zeithaml, V. A., \& Berry, L. L. (1985). A conceptual model of service quality and its implications for future research. the Journal of Marketing, 41-50.

- Poolton, J., \& Barclay, I. (1998). New product development from past research to future applications. Industrial Marketing Management, 27(3), 197-212.

- Santamaría, L., Nieto, M. J., \& Barge-Gil, A. (2009). Beyond formal R\&D: Taking advantage of other sources of innovation in low-and medium technology industries. Research Policy, 38(3), 507-517.

- Santamaría, L., Jesús Nieto, M., \& Miles, I. (2012). Service innovation in manufacturing firms: Evidence from Spain. Technovation, 32(2), 144-155.

- Santamaría, L., Jesus Nieto, M., \& Barge-Gil, A. (2010). The relevance of different open innovation strategies for R\&D performers. Cuadernos de Economía y Dirección de la Empresa, 13(45), 93- 
114.

- Schumpeter, J. A. (1934). The theory of economic development: An inquiry into profits, capital, credit, interest, and the business cycle (Vol. 55). Transaction Publishers.

- Silva, M. J. M., Simões, J., Moreira, J., \& Sousa, G. (2012). Investment and expenditure on innovation activities and innovative capability: empirical evidence from Portuguese services firms and KIBS. International Business Research, 5(2), p114.

- Song, X. M., Thieme, R. J., \& Xie, J. (1998). The Impact of Cross-Functional Joint Involvement Across Product Development Stages: An Exploratory Study. Journal of Product innovation management, 15(4), 289-303.

- Song, M., Dyer, B., \& Thieme, R. J. (2006). Conflict management and innovation performance: An integrated contingency perspective. Journal of the Academy of Marketing Science, 34(3), 341356.

- Song, M., \& Thieme, J. (2009). The Role of Suppliers in Market Intelligence: Gathering for Radical and Incremental Innovation*. Journal of Product Innovation Management, 26(1), 43-57.

- Subramaniam, M., \& Youndt, M. A. (2005). The influence of intellectual capital on the types of innovative capabilities. Academy of Management Journal, 48(3), 450-463.

- Tsai, W., \& Ghoshal, S. (1998). Social capital and value creation: The role of intrafirm networks. Academy of management Journal, 41(4), 464-476.

- West, J., \& Gallagher, S. (2006). Challenges of open innovation: the paradox of firm investment in open-source software. R\&D Management, 36(3), 319331.

- West, J., \& Gallagher, S. (2006). Patterns of open innovation in open source software. Open Innovation: researching a new paradigm, 8.

- Wind, J., \& Mahajan, V. (1997). Editorial: issues and opportunities in new product development: an introduction to the special issue. Journal of Marketing Research, 1-12.

- Wu, W. Y., Chang, M. L., \& Chen, C. W. (2008). Promoting innovation through the accumulation of intellectual capital, social capital, and entrepreneurial orientation. R\&d Management, 38(3), 265277.

- Utterback, J. M., \& Abernathy, W. J. (1975). A dynamic model of process and product innovation. Omega, 3(6), 639-656. 